\title{
ANALISIS FAKTOR-FAKTOR PENYEBAB TERJADINYA DUPLIKASI NOMOR REKAM MEDIS DI PUSKESMAS RAWAT INAP TANJUNGSARI
}

\author{
Tatin Rahmawati ${ }^{1}$, Dinda Oktaviani ${ }^{2}$, Meira Hidayati ${ }^{3}$ \\ Rekam Medis Informasi Kesehatan, Politeknik Piksi Ganesha, Bandung ${ }^{1,2,3}$ \\ piksi.tatinrahmawati.18303090@gmail.com ${ }^{1}$; piksi.dinda.18303190@ gmail.com² ; \\ meirahidayati58@gmail.com ${ }^{3}$
}

Received: 26-06-2021

Revised : 25-07-2021

Accepted: 27-07-2021

\begin{abstract}
Abstrak
Latar Belakang: Sistem penomoran di Puskesmas Rawat Inap Tanjungsari yaitu menggunakan sistem unit (unit numbering system). Sistem ini dapat mempermudah saat melakukan pengambilan dan pengembalian berkas rekam medis. Dari penelitian yang kami lakukan ditemukan masalah yaitu terjadinya duplikasi nomor rekam medis. Hal tersebut disebabkan karena identifikasi yang kurang teliti dan detail, sehingga menyebabkan pasien mendapat lebih dari satu nomor rekam medis.
\end{abstract}

Tujuan: Tujuan penelitian ini yaitu untuk mengidentifikasai faktor-faktor penyebab penomoran ganda.

Metode: Jenis penelitian ini menggunakan rancangan kualitatif dengan metode penilitian deskriftif . Pengumpulan data dilakukan dengan cara wawancara pada petugas pendaftaran dan pada saat mencoba melakukan pendaftaran pasien menggunakan aplikasi SIMPUS.

Hasil: Hasil penelitian menunjukkan bahwa duplikasi nomor rekam medis di Puskesmas Rawat Inap Tanjungsari selama satu bulan penelitian sebanyak 50 dari jumlah kunjungan sebanyak 2276 pasien yaitu sebesar 2,2\%.

Kesimpulan: Dari penelitian yang kami lakukan maka dapat disimpulkam bahwa terdapat $2,2 \%$ terjadinya duplikasi nomor rekam medis dimana hal ini disebabkan karena kurang telitinya petugas pendaftaran saat mengidentifikasi data pasien sehingga jika data pasien tidak ditemukan maka pasien akan dianggap pasien baru dan diberi nomor baru.

Kata kunci: nomor ganda; berkas rekam medis; sistem penomoran.

\begin{abstract}
Background: The numbering system at the Tanjungsari Inpatient Health Center uses a unit numbering system. This system can make it easier to retrieve and file medical records. From our research, we found a problem, namely the occurrence of duplication of medical record numbers. This is due to the patient's ignorance who is less thorough and detailed, so that he gets more than one medical record.
\end{abstract}


Objective: The purpose of this study is to identify the factors that cause double numbering.

Methods: This type of research uses a qualitative design with a descriptive research method. Data collection is done by interviewing the registration officer using and when trying to register the SIMPUS application patient.

Results: The results showed that the duplication of medical record numbers at the Tanjungsari Inpatient Health Center during the one month of the study was 50 from the number of visits by 2276 patients, which was $2.2 \%$.

Conslusion: From our research, it can be concluded that there are $2.2 \%$ of duplication of medical numbers where this is due to the lack of accuracy of the registration officer when taking data so that if patient data is not found, the patient will be considered a new patient and given a new number.

Keywords: double number; medical record file; system numbering.

Coresponden Author : Tatin Rahmawati Email : piksi.tatinrahmawati.18303090@gmail.com

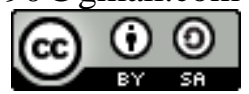

\section{PENDAHULUAN}

Menurut (Indonesia, 44 C.E.) Rumah sakit adalah instusi pelayanan kesehatan yang menyelenggarakan pelayanan kesehatan perorangan secara paripurna yang menyediakan pelayanan rawat inap, rawat jalan, dan gawat darurat. Setiap Rumah sakit mempunyai kewajiban memberikan informasi yang benar tentang pelayanan Rumah Sakit kepada masyarakat, memberi pelayanan kesehatan yang aman, bermutu antidiskriminasi, dan efektif dengan mengutamakan kepentingan pasien sesuai standar pelayanan Rumah Sakit dan menyelenggarakan Rekam Medis.

Menurut (Robi et al., 2021) Rekam Medis adalah berkas yang berisikan catatan dan dokumen tentang identitas pasien, pemeriksaan, pengobatan, tindakan dan pelayanan lain yang telah diberikan kepada pasien. Tujuan utama Rekam medis adalah untuk menunjang tercapainya tertib administrasi dalam mengupayakan peningkatatan pelayanan kesehatan di rumah sakit. Menurut (Robi et al., 2021) pasal 7 Sarana pelayanan kesehatan wajib menyediakan fasilitas yang diperlukan dalam rangka penyelenggaraan rekam medis. Maka dari itu sub unit yang mendukung penyelenggaran Rekam Medis adalah bagian penyimpanan. Penyimpanan adalah salah satu bagian dari unit rekam medis yang bertugas menyimpan rekam medis, menyediakan rekam medis, meretensi rekam medis, dan membantu dalam pelaksanaan pemusnahan rekam medis (Marlina, 2014). Penyimpanan bertanggung jawab terhadap penyimpanan rekam medis. Kecepatan penyedian rekam medis pada bagian peyimpanan mempengaruhi pelayanan terhadap pasien (Hakam, 2018).

Peran penting di bagian penyimpanan selain untuk penyimpanan Rekam Medis, bagian penyimpanan juga harus memperhatikan sistem kerja yang mengutamakan keamanan, kesehatan dan keselamatan dalam bekerja sehingga dapat mengurangi atau bebas dari kecelakaan kerja yang pada akhirnya dapat meningkatkan sistem dan produktifitas kerja, terutama pada saat pengambilan Rekam Medis (Simanjuntak \& Sirait, 2018).

Menurut (Salikunna \& Towidjojo, 2011) Kesehatan dan Keselamatan Kerja adalah upaya untuk memberikan jaminan keselamatan dan meningkatkan derajat 
kesehatan para pekerja/buruh denan cara pencegahan kecelakaan dan penyakit akibat kerja, pengendalian bahaya ditmpat kerja, promosi kesehatan, pengobatan dan rehabilitasi. Upaya Kesehatan dan Keselamatan kerja menyangkut tenaga kerja, cara/metode kerja, alat kerja, proses kerja dan lingkungan kerja.

Menurut (Rustiyanto \& Rahayu, 2011) lingkungan kerja merupakan tempat bekerja seseorang dalam melaksanakan segala aktivitasnya. Sebagai perekam medis, maka diperlukan ruang kerja rekam medis yang mencakup aspek ergonomi agar menimbulkan kenyamanan, kesehatan dan keselamatan kerja sehingga proses bekerja menjadi efisien dan efektif. Ketersediaan berkas rekam medis secara cepat dan tepat pada saat dibutuhkan akan sangat membantu mutu pelayanan kesehatan yang diberikan kepada pasien. Berkas rekam medis lama sulit ditemukan sehingga proses pencarian berkas rekam medis pasien di rak penyimpanan membutuhkan waktu yang lama karena terjadi duplikasi nomor rekam medis pasien serta ketidaksesuaian urutan penyimpanan rekam medis sehingga sering terjadi (missfile) walaupun di Puskesmas Tanjungsari sudah menggunakan tracer. Maka penulis bertujuan melakukan penelitian terkait faktor yang mempengaruhi terjadinya duplikasi nomor rekam medis..

\section{METODE PENELITIAN}

Metode penelitian yang digunakan adalah penelitian deskriptif yaitu menggambarkan hasil penelitian sesuai dengan penelitian untuk menghasilkan gambaran sesuai dengan keadaan yang sebenarnya. Teknik pengumpulan data yang digunakan peneliti adalah wawancara, observasi dan studi dokumentasi. Peneliti melakukan wawancara terhadap petugas pendaftaran yang bertanggung jawab dengan pemberian nomor rekam medis pasien. Observasi yang dilakukan berdasarkan atas pengalaman langsung yaitu melakukan pencarian nomor rekam medis jika pasien lama dan pemberian nomor rekam medis jika pasien baru pada aplikasi SIMPUS. Teknik pengumpulan data dengan studi dokumentasi pada penelitian ini dilakukan dengan cara mengamati pasien yang memiliki nomor rekam medis ganda lalu dilakukan pencarian pada aplikasi SIMPUS untuk melihat nomor rekam medis mana yang sudah terisikan catatan pengobatan.

Instrumen yang digunakan dalam penelitian ini antara lain wawancara dan alatalat yang digunakan. Panduan wawancara merupakan daftar pertanyaan yang telah dibuat oleh peneliti sebelum melakukan penelitian. Dalam penelitian ini peneliti mengajukan pertanyaan sebanyak sepuluh pertanyaan yang diajukan kepada kepala rekam medis dan lima orang petugas pendaftaran Puskesmas Rawat Inap Tanjungsari. Alat-alat yang digunakan untuk mendukung instrumen pengumpulan data adalah kamera dan alat tulis untuk mencatat.

Analisis data dalam penelitian ini meliputi reduksi data, penyajian data dan penarikan kesimpulan. Reduksi data dalam penelitian ini adalah dengan memilah hasil wawancara, observasi, dan studi dokumentasi. Penyajian data yang dilakukan yaitu data disajikan dalam bentuk teks. Kesimpulan yang diperoleh dari penelitian ini adalah faktorfaktor yang menyebabkakn terjadinya duplikasi rekam medis. 


\section{HASIL DAN PEMBAHASAN}

\section{A. Hasil Penelitian}

Pelaksaan sistem penomoran yang di pakai di puskesmas tanjungsari adalah unit numbering system / sistem penomoran unit dimana satu pasien hanya mendapatkan satu nomor rekam medis saat melakukan pendaftaran. Sistem pendaftaran saat ini menggunakan aplikasi SIMPUS. Berdasarkan hasil observasi dan wawancara, langkahlangkah penomoran berkas rekam medis di Puskesmas Rawat Inap Tanjungsari antara lain:

a. Setelah pasien dipanggil sesuai nomor antrian maka petugas akan menanyakan KIB untuk yang pasien tidak membawa KIB maka petugas akan bertanya "apakah sudah pernah berobat kesini sebelumnya?" jika pernah maka petugas akan meminta pasien untuk menuliskan nama lengkap, tanggal lahir dan alamat pasien. Jika tidak pernah maka akan dianggap sebagai pasien baru kemudian petugas akan meminjam KTP untuk mengisi data pasien.

b. Petugas akan memasukan nomor rekam medis yang tertera pada KIB atau tanggal lahir pasien pada aplikasi SIMPUS lalu mencarinya.

c. jika terdapat pasien yang memiliki dua nomor rekam medis maka petugas akan memilih salah satu nomor rekam medis yang sering digunakan pasien untuk berobat dan petugas akan menghapus nomor rekam medis yang tidak digunakan.

Kami melakukan pengambilan data double medrec selama satu bulan. Tercatat pada bulan April 2021 jumlah kunjungan pasien rawat jalan maupun rawat inap yaitu sebanyak 2267 pasien dimana terdapat sekitar 50 pasien yang mempunyai nomor rekam medis ganda. Berikut merupakan hasil perhitungan yang kami dapatkan dari hasil penelitian selama satu bulan:

$$
\frac{50}{2267}=0,022 \times 100 \%=2,2 \% \text {. }
$$

Maka masih terdapat 2,2\% kesalahan yang terjadi saat melakukan pemberian nomor rekam medis. Meskipun dengan hasil dibawah $10 \%$ tetap saja tidak sesuai dengan pedoman yang berlaku bahwa kekonsistenan pengisian DRM ( Dokumen Rekam Medis) harus berada di rate 100\% sebagaimana yang dikemukakakn oleh (Mardian, 2016), artinya tidak boleh ada duplikasi nomor rekam medis, karena nomor rekam medis penting untuk pengidentifikasian data pasien serta untuk menjaga mutu dari sistem pelayanan itu sendiri.

\section{B. Pembahasan}

Sistem yang berkaitan dengan penomoran berkas rekam medis yaitu sistem penyimpanan. Di puskesmas Tanjungsari menggunakan sistem penyimpanan secara Sentralisasi dimana semua berkas baik Rawat Inap, Rawat Jalan serta UGD disimpan di satu ruangan filling. Pengelolaan penomoran rekam medis yaitu untuk menunjang tercapainya tertib administrasi dalam rangka upaya mencapai tujuan rumah sakit, yaitu peningkatan mutu rumah sakit dalam sistem penomoran, (YanMed \& Depkes, 1997). Menurut (Lawang, n.d.) Jenis sistem penomoran ada tiga macam sistem pemberian nomor pasien masuk (Admission Numbering System) sistem manapun yang dipakai, setiap rekam medis baru harus mendapatkan nomor yang diurut secara kronologis dan nomor tersebut digunakan oleh seluruh unit atau bagian di Rumah Sakit yang bersangkutan. 
Ketidaksesuaian sistem penomoran terjadi karena petugas tidak memahami sistem yang telah diterapkan.Hal ini sesuai dengan hasil penelitian tentang pelaksanaan sistem penomoran Unit Numbering System(UNS)yaitu terjadi duplikasi nomor rekam medis disebabkan karena kurang telitinya petugas pendaftaran dalam mencari data identitas pasien, sehingga jika data pasien tidak ditemukan maka pasien akan dianggap pasien baru dan diberi nomor baru (Siti , 2015). Padahal solusi yang dilakukan petugas tersebut tidak sesuai dengan konsep sistem penomoran UNS yaitu satu pasien hanya memiliki 1 (satu) nomor rekam medis yang digunakan untuk setiap kali berobat.

Berdasarkan hasil penelitian masih ditemukannya petugas yang kurang patuh dalam menjalankan prosedur pendaftaran serta petugas pendaftaran kurang memperhatikan dan disiplin dalam melakukan pendaftaran sesuai prosedur yang berlaku. Dampak dari aspek yang tidak dipatuhi petugas, pelayanan pasien menjadi kurang baik karena data pasien tidak akurat sehingga terjadi duplikasi data pasien, proses pencarian data pasien sulit ditemukan dan petugas kerja dua kali untuk memperbaiki data pasien.

Pengetahuan seseorang didapat dari pengamatan tentang suatu objek tertentu. Semakin banyak aspek positif dari objek yang diketahui, akan menimbulkan sikap positif terhadap objek tertentu ( Notoatmodjo, 2010). Menurut (Faruq, 2021), pendidikan seseorang dipersiapkan untuk bekal agar siap tahu, mengenal dan mengembangkan metode berpikir secara sistematik agar dapat memecahkan masalah yang dihadapi dalam kehidupan sehari-hari.

Di Puskesmas Rawat Inap Tanjungsari terdapat lima orang petugas pendaftaran pasien yang dibawahi oleh seorang kepala rekam medis. Tingkat pendidikan petugas pendaftaran terbanyak berasal dari lulusan SMK dan hanya ditemukan dua orang petugas yang berlatar pendidikan D3 Rekam Medis termasuk kepala rekam medis dan satu orang berlatar pendidikan S1 Teknik Informatika. Dari hal tersebut petugas tidak memiliki kompetensi yang harus dimilki oleh seorang perekam medis. Menurut (Sulistyarini, 1996) tentang tenaga kesehatan pasal 1 dan 3 perekam medis termasuk tenaga kesehatan (tenaga keteknisian medis) dan tenaga kesehatan wajib memiliki pengetahuan dan keterampilan di bidang kesehatan yang dinyatakan dengan ijazah-ijazah lembaga pendidikan.

Menurut (Budi, 2011) menyatakan bahwa petugas penerimaan pasien harus menguasai alur pelayanan pasien, alur berkas rekam medis, dan prosedur penerimaan pasien sehingga petugas dapat memberikan pelayanan dan informasi yang tepat dan cepat. Menurut (Arianti et al., 2020) dan dimana telah terjadi penomoran ganda, bahwa satu pasien terdapat nomor rekam medis sebanyak dua nomor rekam medis, bawa faktor penyebab terjadinya penomoran ganda tersebut yaitu petugas yang kurang teliti atau ketidakmampuan seseorang dalam memenuhi kebutuhan puskesmas sehingga, petugas dalam menjalankan tugasnya kurang baik dan kurang teliti.

Hasil telaah di Puskesmas Rawat Inap Tanjungsari sudah terdapat kebijakan pemberian NRM (Nomor Rekam Medis) yang terkandung dalam SOP, dimana SOP tersebut memuat semua tentang prosedur pelayanan dan pelaksanaan rekam medis. Pemberian nomor yaitu dimana setiap pasien datang pertama kali ke puskesmas akan mendapat satu NRM (Nomor Rekam Medis) yang akan dipakai selamanya untuk kunjungan berikutnya. Sesuai dengan penelitian yang dilakukan oleh (Pinerdi et al., 2020) bahwa dalam yang menyebabkan terjadinya duplikasi karena kebujakan yang menyatu di dalam SOP, sehingga perlu adanya kebijakan pelayanan rekam medis yang mengacu pada prosedur kerja Puskesmas agar lebih baik. Adanya kebijakan dalam suatu lingkungan kerja akan sangat berpengaruh bagi kelangsungan kerja.

Beberapa akibat bila terjadi duplikasi penomoran rekam medis diantaranya, rak rekam medis akan cepat penuh, pelayanan terhambat karena lamanya pencarian berkas rekam medis, adanya komplen dari poliklinik karena isi rekam medis tidak berkesinambungan, biaya menjadi meningkat karena penggunaan formulir yang lebih banyak. Sebaiknya duplikasi nomor rekam medis tidak seharusnya terjadi, sebab menurut 
Permenkes 269 tahun 2008, rekam medis murapakan berkas yang berisikan catatan dan dokumen tentang identitas pasien, pemeriksaan, pengobatan, tindakan dan pelayanan lain yang telah di berikan kepada pasien, Sehingga saat terjadinya duplikasi penomoran maka pengobatan pasien menjadi tidak berkesinambungan. Seluruh petugas pendaftaran diharapkan lebih teliti lagi saat melakukan input nomor rekam medis cek.

\section{KESIMPULAN}

Dari penelitian yang kami lakukan maka dapat disimpulkam bahwa terdapat 2,2\% terjadinya duplikasi nomor rekam medis dimana hal ini disebabkan karena kurang telitinya petugas pendaftaran saat mengidentifikasi data pasien sehingga jika data pasien tidak ditemukan maka pasien akan dianggap pasien baru dan diberi nomor baru (Rokaiyah \& Setijaningsih, n.d.). Padahal solusi yang dilakukan petugas tersebut tidak sesuai dengan konsep sistem penomoran UNS (Unit Numbering System) yaitu satu pasien hanya memiliki 1 (satu) nomor rekam medis yang digunakan untuk setiap kali berobat. Kepala rekam medis seharusnya membuat kebijakan pemberian nomor rekam medis berupa buku pedoman yang memuat semua tentang pelayanan dan pelaksanaan rekam medis untuk menghindari terjadinya duplikasi nomor rekam medis. Karena selama ini kebijakan pelayanan maupun pelaksanaan rekam medis masih mengacu pada SOP yang ada.

\section{BIBLIOGRAFI}

Arianti, s. D., masyfufah, 1., sulistyoadi, s., \& wijaya, f. (2020). Faktor-faktor yang mempengaruhi duplikasi penomoran berkas rekam medis di siloam hospitals surabaya. Jurnal manajemen kesehatan yayasan rs. Dr. Soetomo, 6(2), 179-191.

Budi, s. C. (2011). Manajemen unit kerja rekam medis. Yogyakarta: quantum sinergis media.

Farradika, y., umniyatun, y., nurmansyah, m. I., \& jannah, m. (2019). Perilaku aktivitas fisik dan determinannya pada mahasiswa fakultas ilmu-ilmu kesehatan universitas muhammadiyah prof. Dr. Hamka. Arkesmas (arsip kesehatan masyarakat), 4(1), $134-142$.

Faruq, m. D. (2021). Pengaruh keterampilan dan tingkat pendidikan terhadap produktivitas kerja karyawan pada bagian produksi di cv surya kencana food jombang. Stie pgri dewantara.

Hakam, f. (2018). Analisis penyediaan rekam medis pasien rawat jalan berdasarkan standar operasional prosedur (sop) di puskesmas x. Jurnal manajemen informasi dan administrasi kesehatan (jmiak), 1(1).

Indonesia, p. (44 c.e.). Undang-undang republik indonesia nomor 44 tahun 2009 tentang rumah sakit.

Lawang, d. P. (n.d.). Analisis efektivitas sop pelaksanaan penyimpanan berkas rekam medis.

Mardian, a. H. (2016). Analisis efisiensi pelayanan rawat inap rumah sakit daerah 
balung tahun 2015 melalui pendekatan barber-johnson.

Marlina, e. V. I. (2014). Tinjauan pelayanan rekam medis bagian filing di puskesmas bejen kabupaten temanggung tahun 2014. Eprints. Dinus. Ac. Id.

Notoatmodjo, s. (2010). Ilmu perilaku kesehatan.

Pinerdi, s., ardianto, e. T., nuraini, n., \& nurmawati, i. (2020). Tingkat penerimaan dan penggunaan sistem informasi manajemen puskesmas kabupaten jember. J-remi: jurnal rekam medik dan informasi kesehatan, 1(2), 104-112.

Robi, h., maiyestati, m., \& zarfinal, z. (2021). Implementasi peraturan menteri kesehatan republik indonesia nomor 269 tahun 2008 tentang rekam medis terhadap klaim bpjs di rsud sungai dareh. Universitas bung hatta.

Rokaiyah, s., \& setijaningsih, r. A. (n.d.). Tinjauan pelaksanaan sistem penomoran di tempat pendaftaran pasien rumah sakit permata bunda purwodadi tahun 20015.

Rustiyanto, e., \& rahayu, w. A. (2011). Manajemen filing dokumen rekam medis dan informasi kesehatan. Yogyakarta: politeknik kesehatan permata indonesia.

Salikunna, n. A., \& towidjojo, v. D. (2011). Penerapan sistem manajemen kesehatan dan keselamatan kerja di rumah sakit bersalin pertiwi makassar. Biocelebes, 5(1).

Simanjuntak, e., \& sirait, 1. W. O. Menkes. Ri. (2018). Faktor-faktor penyebab terjadinya missfile di bagian penyimpanan berkas rekam medis rumah sakit mitra medika medan tahun 2017. Jurnal ilmiah perekam dan informasi kesehatan imelda (jipiki), 3(1), 370-379.

Siti, r. (2015). Tinjauan pelaksanaan sistem penomoran di tempat pendaftaran pasien rumah sakit permata bunda purwodadi tahun 20015. Skripsi, fakultas kesehatan

Sulistyarini, d. (1996). Sanksi hukum terhadap penyalahgunaan visa di indonesia ditinjau dari peraturan pemerintah republik indonesia nomor 32 tahun 1984. Prodi ilmu hukum unika soegijapranata.

Yanmed, d., \& depkes, r. I. (1997). Pedoman pengelolaan rekam medis rumah sakit di indonesia. Depkes ri, jakarta.

(C) 2021 by the authors. Submitted for possible open access publication under the terms and conditions of the Creative Commons Attribution (CC BY SA) license (https://creativecommons.org/licenses/by-sa/4.0/). 